Running Head: SEGMENTATION OF ROOT AND PATTERN MORPHOLOGY

Segmentation of Root and Pattern Morphology

Sara Finley and Elissa L. Newport ${ }^{\mathrm{b}}$

aPacific Lutheran University

${ }^{\mathrm{b}}$ Georgetown University

Acknowledgements: We are grateful to Patricia Reeder, Neil Bardhan, Neil Snider, Carrie Miller, Kelly Johnston, Lily Schieber, Anna States, Emily Kasman, Cristina Flores, Elizabeth Wiemers, and to members of the Aslin-Newport lab. This research was supported in part by NIH grant DC00167 to E. Newport, HD37082 to R. Aslin \& E. Newport, and NIH training grant T32DC000035.

Address correspondence to:

Sara Finley

Department of Psychology

Pacific Lutheran University

12180 Park Ave S

Tacoma, WA 98447

finleysr@plu.edu 


\begin{abstract}
Morphology is the study of how form and meaning are combined to form complex words. While previous studies of morphology learning rely on semantic associations of continuous affixes (e.g., prefixes and suffixes), the present study focuses on the learnability of non-continuous (nonconcatenative) forms, without the use of semantic information. We performed three artificial grammar learning experiments testing the types of information that adult, English speaking learners can extract from hearing words made up of CCC 'roots'. In Experiment 1, participants were exposed to $24 \mathrm{CVCVC}$ words made up of $12 \mathrm{CCC}$ roots and four VV residues, repeated 15 times. In Experiments 2 and 3 the number of CCC items was increased to 72 (repeated five times), but with four additional templates (e.g., CVCCV in addition to CVCVC) in Experiment 2, and the addition of a prefix in Experiment 3. The results were parallel across all three experiments: participants could readily identify familiar items compared to both ungrammatical and novel grammatical items, and could correctly identify novel words compared to ungrammatical items, but only when the ungrammatical item was sufficiently different from the items heard in training. These results suggest that while learners can extract discontinuous information from lexical items, learners rely heavily on their memory for these lexical items, suggesting a possible bias against learning non-concatenative morphology.
\end{abstract}




\section{Segmentation of Root and Pattern Morphology}

Language learning involves finding the structure and meaning in words and sentences. Morpheme segmentation is the process of breaking words down into their component parts, in order to build a system that generates novel words, finds meaningful similarities between related words, and builds a set of morphemes and morphological structure. In most languages, the majority of morphology involves concatenative morphology, where morphemes consist of continuous strings of phonemes, in which roots form a base that allow affixes to attach to the beginning of the root (as a prefix), or the end of the root (as a suffix). While the computational problem of segmenting concatenative morphology is large (e.g., the learner must differentiate between the can in candy from the can in canning and canned), the process is made easier because the probabilities are applied over adjacent and continuous elements. In nonconcatenative morphology, most notably root and pattern morphology, the morphological elements are non-adjacent. For example, in languages with root and pattern morphology such as Arabic and Hebrew, consonantal roots are filled into various templatic structures. For example, in Modern Hebrew, gidel 'to raise', gadal 'to grow', and higdil 'to enlarge' are all related by the consonantal root /gdl/and the semantic meaning of 'large size' (Bat-El, 1994) .

The problem for the learner in a root and pattern system is to extract the consonantal roots from the various templates. It is well-known that learning non-adjacent dependencies poses a particular challenge for language learning (Bonatti et al., 2005; Endress \& Bonatti, 2007; Frost \& Monaghan, 2016; Gomez, 2002; Gomez \& Maye, 2005; Misyak et al., 2009; Misyak \& Christiansen, 2007; Newport \& Aslin, 2004). This is an issue both in terms of non-adjacent dependencies among words in sentences (Wilson et al., 2020), but also within words in phonological patterns like vowel and consonant harmony (Finley, 2011,2015; McMullin \& 
Hansson, 2014, 2019), morphological patterns like non-concatenative morphology (Drake, 2018; Fullwood, 2018; Fullwood \& O’Donnell, 2013).

Findings from previous studies on non-adjacent patterns in language have demonstrated that non-adjacent patterns are restricted (Wilson et al., 2020); they appear only in certain contexts, and learners appear to be biased against non-adjacent patterns when they appear outside of restricted contexts. One reason that non-adjacent morphological patterns are difficult to learn is the computational complexity of possible number of parses of a given word. As Fullwood (2018) notes, as the length of the word increases, the number of parses increases, but more so for non-concatenative morphology. For example, a concatenative parse of canning ([kænın]) into

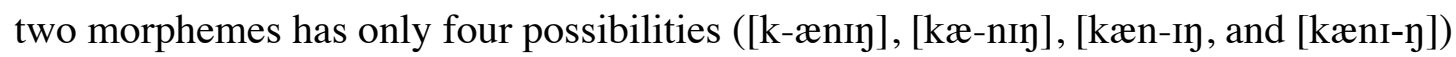
but a non-concatenative parse of canning as two morphemes has all the possibilities of the concatenative parse, plus several additional parses (e.g., [kn]-[æı ], [ky]-[ænı ], [knı ]-[æ], etc.) and this increases with the number of possible morphemes in a word (e.g., one could parse [kænın] as five individual morphemes), and the length of the word. While constraints on nonconcatenative morphology, such as consonantal roots, can reduce the number of possible parses, the general computational problem for non-adjacent dependencies in phonology is high.

Previous studies on artificial grammar learning of non-adjacent dependencies across words in speech segmentation have suggested that learners use several cues to mitigate biases against non-adjacent dependencies (Wilson et al., 2020). These include phonetic and phonological effects such as prosodic cues and perceptual similarity (Grama et al., 2016; Newport \& Aslin, 2004; Onnis et al., 2005), psycholinguistic factors such as variability (Gomez, 2002), edge effects (Marchetto \& Bonatti, 2013; Peña et al., 2002), and attentional factors (de Diego-Balaguer et al., 2016; Toro et al., 2011), such as top-down processing (Wang et al., 2017). 
However, it is not entirely clear which cues are necessary or sufficient for learning non-adjacent dependencies. For example, it is unclear whether pauses in the speech stream help to provide linguistic structure to help build non-adjacent dependencies, or if the pauses serve to direct the learner's attention to the relevant relationships (Wang \& Mintz, 2018).

Because most previous research on learning non-adjacent patterns has focused on the sentence level, or with speech segmentation (Drake, 2018; Newport \& Aslin, 2004), less is known about how morpheme segmentation applies in non-concatenative systems. The present study explores how different templates for non-adjacent dependencies in root and pattern morphology can affect morpheme segmentation. The goal of the present study is to better understand what types of information speakers learn when exposed to non-concatenative morphology systems, when presented with words without any cues to meaning.

There are several possible strategies that learners may make when learning a root and pattern system. One is based on the informativity of consonant versus vowel patterns. While Gomez (2002) showed that variability is important for the intervening items in learning nonadjacent dependencies between words, it could be that the variability helped learning because the intermediate items were unpredictable, and thus, uninformative. If a lack of information allows learners to find regularities, then invariability might serve the same purpose. For example, in a structure AqB where A and B form a non-adjacent dependency, if the intermediate structure is always the same lexical item, then q becomes uninformative as it is highly predictable, and attention is drawn away from q towards A and B (e.g., 'q' is highly predictable in the sentences 'flug q gamit', 'pupe q volim', 'lubit q mebe'). In the case of non-concatenative morphology, one could have many different possible combinations of consonantal roots, but only a few vowel patterns to fill into a template. If there are very few vowel combinations, but many possible 
consonantal combinations, learners may be more likely to discover regularities among the consonants despite interleaving vowels, because the vowel patterns may be uninformative.

Another way to highlight the predictability of the consonant patterns is to have many different types of words (often referred to as templates) for which the consonants can be applied. For example, [patak], [aptak], [apataka], and [patka] are four words that all have /ptk/ as the consonants, and /a/ as the vowel; what varies is the syllable structure. If a language has a fixed way that segments can be fit into a large number of syllable structures, then it may be possible for learners to sort out the grammatical regularities that differentiate between the roots and the patterns. In fact, natural languages with non-concatenative morphology, typically have this type of variation between roots and patterns (McCarthy \& Prince, 1990). In natural language rootand-pattern morphology, the variation occurring across words typically involves roots (e.g., consonant frames) that fit around many different types of vowel patterns (e.g., VCVCVC, CVCVCV, VCCVC, and CVCCV).

Edge effects may also help draw learners towards regularities in the speech stream. By paying attention to beginnings and ends of words, learners may find regularities in terms of the templatic structure of what consonants go together in the words. Since beginnings and ends of words are highly salient (Beckman, 1997), speakers may draw regularities about word structure from the beginnings and ends of words. It is important to note that while learners may make use of edge information to learn novel categories, learners can find categories even when edges are purposefully uninformative (Reeder et al., 2013). In addition, in natural languages with nonconcatenative morphology also contain concatenative morphology, meaning that a nonconcatenative template could serve as a root in which a prefix or a suffix is attached. The role of edges can be tested in two ways. First, test items can probe the ability to distinguish between 
novel words and ungrammatical items that preserve some edge effects. If learners can successfully identify these items, it suggests that the participants learned more than rules about the edges. Second, training can also include prefixes or suffixes in addition to the general templates. If learners rely on the edges of the words to parse the CVCVC templates, than including a prefix, for example, would hinder this, and learning should decrease.

In three experiments, English-speaking participants were exposed to words from an artificial miniature language with a non-concatenative system based in root and pattern morphology. Participants in Experiment 1 were exposed to CVCVC templates, while participants in Experiment 2 were exposed to the same CVCVC templates, plus additional templates conforming to possible syllable structures, in order to test whether this type of difference in variation would induce learning of the $\mathrm{CCC}$ consonantal roots in a miniature non-concatenative morphological system. Participants in Experiment 3 were exposed to the same CVCVC templates as Experiment 1, but with an additional prefix.

\section{Experiment 1}

Participants in Experiment 1 were exposed to a root and pattern morphology system where 12 CCC consonantal roots were fit into CVCVC templates, and only four vowel residues.

\section{Method}

\section{Participants}

All participants were adult English speakers who were recruited at a small liberal arts college in the Pacific Northwest of the United States. Seventeen participants were included in the final analysis. No participant reported knowledge of a language with regular non-concatenative morphology (e.g., Arabic or Hebrew). 


\section{Materials}

Participants in Experiment 1 were exposed to a miniature language that was based on a 'root and pattern' morphology system. There were 12 consonantal roots (CCC), and four vowel residues (VV) that fit into the CVCVC template. Participants were exposed to only 24 of the 48 possible $24 \mathrm{C}_{1} \mathrm{~V}_{\mathrm{A}} \mathrm{C}_{2} \mathrm{~V}_{\mathrm{B}} \mathrm{C}_{3}$ words, repeated 15 times each. The $12 \mathrm{CCC}$ consonantal roots were each made of three consonants from the set /p, t, k, b, d, g, f, s, z, v/, such as /ptk/, /bdg/ and /ftk/. The vowel patterns were created from the set [a, e, i, o, u] (to form $\mathrm{C}_{1} \mathrm{~V}_{\mathrm{A}} \mathrm{C}_{2} \mathrm{~V}_{\mathrm{B}} \mathrm{C}_{3}$ ). Each consonantal root was paired with two of the possible vowel patterns. Care was taken so that each consonant and vowel appeared equally often in each position, and that all the words were potential English words, but no CVCVC form was an actual English lexical item ${ }^{1}$. Examples of training stimuli can be found in Table 1 , below ${ }^{2}$.

\section{INSERT TABLE 1 ABOUT HERE}

Learnability $^{3}$ of the miniature language was assessed with a two-alternative forced-choice test that contained five different types of test items (eight of each). The first test type, referred to as Old-Scrambled items, required participants to choose between words that were heard in training, and an ungrammatical word that was created by reversing the final two consonants of a

\footnotetext{
${ }^{1}$ An additional language (referred to as Language B) was created and run with an additional 17 participants. Language B was not included in the paper to be consistent with Experiments 2-3, which could not include Language B due to experimenter error. In Experiment 2, participants in Language B were given an incorrect number of training items, which were repeated 10 times instead of five. In Experiment 3, participants in Language B were missing two items in the training set. In addition, two items in the New-NonWordHybrid test items in Language B did not actually test for a nonword hybrid. The same pattern of results was obtained when Experiment 1 was analyzed with both Language A and B.

${ }^{2}$ Full sets of materials and analysis code can be found at- https://osf.io/6xkrp/

${ }^{3}$ The test items in Experiment 1 were identical to those in another set of experiments from Finley and Newport (2020). For this reason, there is duplication in the writing of this Method section.
} 
word heard in training (e.g., /bidig/ vs. *4/bigid/, $C_{1} V_{A} C_{2} V_{B} C_{3}$ vs. $C_{1} V_{A} C_{3} V_{B} C_{2}$, where the subscripts 1,2, and 3 are given to indicate the order of the consonants heard in the training items, and the subscripts A and B are given to indicate the order of the vowels heard in training). Because one can choose the correct item simply through memorization, it is predicted that participants should perform above chance on these items.

The other four types of test items probed whether participants can generalize the CCC roots to one of the word combinations formed by the consonantal root and vowel patterns that are possible (i.e., grammatical) but were not heard in training. New-Scrambled(Hard) test items were of the same format as Old-Scrambled items, except that the 'correct' (grammatical) item was not heard in training. Instead, the grammatical item consisted of consonants and vowels that had appeared in training but not in the same word (e.g., /badug/vs.*/bigad/, $\mathrm{C}_{1} \mathrm{~V}_{\mathrm{X}} \mathrm{C}_{2} \mathrm{~V}_{\mathrm{Y}} \mathrm{C}_{3} \mathrm{vs}$.

$\mathrm{C}_{1} \mathrm{~V}_{\mathrm{A}} \mathrm{C}_{3} \mathrm{~V}_{\mathrm{B}} \mathrm{C}_{2}$, where the subscripts $\mathrm{X}$ and $\mathrm{Y}$ refer to a vowel pattern heard in training but was not paired not with the specific CCC consonantal root). These New-Scrambled items are considered 'hard' because the scrambled item preserves the first syllable $\mathrm{C}_{1} \mathrm{~V}_{\mathrm{A}}$ of the familiar item. Thus, the first syllable in the ungrammatical item will be familiar to participants, but the first syllable in the grammatical, novel item will be unfamiliar. These items can be used to test some aspects of edge effects, since the first consonant is the same in both options. Participants must select the correct item based on the order of the final two consonants in relation to the first.

New-Scrambled(Easy) items compared a grammatical novel item (1X2Y3, as in NewScrambled(Hard) items) to an ungrammatical item that was created by rearranging all three consonants of a word heard in training (e.g., /dizag/vs.*/gudiz, $\mathrm{C}_{1} \mathrm{~V}_{\mathrm{X}} \mathrm{C}_{2} \mathrm{~V}_{\mathrm{Y}} \mathrm{C}_{3}$ vs. $\mathrm{C}_{3} \mathrm{~V}_{\mathrm{A}} \mathrm{C}_{1} \mathrm{~V}_{\mathrm{B}} \mathrm{C}_{2}$ ). These New-Scrambled items are considered 'easy' because both the initial and final consonant

$4 *$ indicates an ill-formed, or ungrammatical word. 
have been moved in the ungrammatical 'scrambled' item, increasing the perceptual distance from the training set.

The fourth type of test item probed whether participants learned that the order of the consonantal roots was specific to the CCC root, rather than a more general phonotactic constrained (e.g., if exposed to /patak/ that they learned that [p], [t] and [k] may appear together, in that order, rather than just that words may start with [p]). These items pitted a novel, but grammatical item $\left(\mathrm{C}_{1} \mathrm{~V}_{\mathrm{X}} \mathrm{C}_{2} \mathrm{~V}_{\mathrm{Y}} \mathrm{C}_{3}\right)$ with an ungrammatical non-word that was created by taking the first consonant from one consonantal root, and the final two consonants from a different consonantal root, referred to as a non-word hybrid. These items were referred to as NewNonWord Hybrid (NWH) items $\left(\mathrm{C}_{1} \mathrm{~V}_{\mathrm{A}}\right)\left(\mathrm{C}_{2} \mathrm{~V}_{\mathrm{B}} \mathrm{C}\right)$. If participants learned the consonantal root, participants will select the novel item significantly above chance, but if participants parse the training items as syllables, rather than as non-continuous CCC roots, then participants will prefer the NonWord Hybrid (NWH) items.

Because participants were exposed to a small number of items (24) repeated several times (15), it is possible that learners will not extract a general pattern, but memorize the different words. One way to test for abstract representations is to compare whether learners can differentiate between familiar and novel grammatical items. This fifth set of test items, referred to as Old-New items, compared familiar items $\left(\mathrm{C}_{1} \mathrm{~V}_{\mathrm{A}} \mathrm{C}_{2} \mathrm{~V}_{\mathrm{B}} \mathrm{C}_{3}\right)$ with a novel item $\left(\mathrm{C}_{1} \mathrm{~V}_{\mathrm{X}} \mathrm{C}_{2} \mathrm{~V}_{\mathrm{Y}} \mathrm{C}_{3}\right)$. These items were coded as 'correct' when the participant selected the Old item, even though both items are grammatical. Failure to score above chance on these items suggests that learners have formed an abstract grammar, as participants find novel and familiar items equally acceptable. Examples of test items can be found in Table 2. 
All stimuli were recorded in a sound-attenuated booth by an adult female native English speaker. While the speaker was aware that the stimuli were to be used for an artificial grammar learning study, the speaker was unaware of the hypothesis of the study. Tokens were individually recorded. Each token was spoken four times in list format. A single token was chosen from the second or third element of the set in order to keep the prosody as uniform as possible. The first and last elements were avoided to avoid the intonation of first and last elements in a list. The speaker was told to speak each word as clearly and accurately as possible (without reducing vowels). Stress was placed on the final syllable. All stimuli were normalized to $70 \mathrm{~dB}$.

\section{Procedure}

Participants were told that they would be listening to words from a language that they had never heard before, and that their task was to listen to the way the novel language sounded, but that they need not try and memorize the forms. The training consisted of 24 tri-syllabic items repeated 15 times each.

The training was followed by a two-alternative forced-choice test that contained 40 the items discussed above (in a random order). Participants were told that they would hear two words, one belonging to the language they heard, and the other not belonging to the language. If they believed the first word belonged to the language, they were to press the 'a' key; if they believed the second word belonged to the language, they were to press the ' 1 ' key. Participants were told to respond as quickly and accurately as possible, but no time limit was given for responses. The experiment took approximately 24 minutes to complete.

\section{Results}

Results (means and standard errors) from Experiments 1-2 can be found in Figure 1. All data were entered into generalized mixed effects models using the glmer function in the lme4 
package (Bates et al., 2015) in R (R Development Core Team, 2018) in RStudio (RStudio Team, 2020), with the maximal model that would converge, as justified by the experimental design (Barr et al., 2013). This included random intercepts for items and subjects ${ }^{5}$. To test whether each of the five test items were significantly different from chance, a separate model was run with the relevant test item set as the baseline, with a significant intercept interpreted as a significant difference from chance.

\section{INSERT FIGURE 1 ABOUT HERE}

Correct responses to Old-Scrambled $\left(\mathrm{C}_{1} \mathrm{~V}_{\mathrm{A}} \mathrm{C}_{2} \mathrm{~V}_{\mathrm{B}} \mathrm{C}_{3}\right.$ vs. $\left.\mathrm{C}_{1} \mathrm{~V}_{\mathrm{A}} \mathrm{C}_{3} \mathrm{~V}_{\mathrm{B}} \mathrm{C}_{2}\right)$ items, with a mean of $0.83, C I \pm 0.046$, were selected at a rate significantly above chance, $\beta=1.68, S E=0.30, z=$ 5.64, $p<0.001$. Correct responses to New-Scrambled(Easy) $\left(\mathrm{C}_{1} \mathrm{~V}_{\mathrm{X}} \mathrm{C}_{2} \mathrm{~V}_{\mathrm{Y}} \mathrm{C}_{3}\right.$ vs. $\left.\mathrm{C}_{3} \mathrm{~V}_{\mathrm{A}} \mathrm{C}_{1} \mathrm{~V}_{\mathrm{B}} \mathrm{C}_{2}\right)$ items, with a mean of $0.74, C I \pm 0.074$ were selected at a rate significantly above chance, $\beta=$ 1.12, $S E=0.27, z=4.13, p<0.001$. Correct responses to New-Non-Word Hybrid (NWH) items $\left(\mathrm{C}_{1} \mathrm{~V}_{\mathrm{X}} \mathrm{C}_{2} \mathrm{~V}_{\mathrm{Y}} \mathrm{C}_{3}\right.$ vs. $\left.\left(\mathrm{C}_{1} \mathrm{~V}\right)\left(\mathrm{C}_{2} \mathrm{VC}_{3}\right)\right)$ with a mean of $0.651, C I \pm 0.081$, were selected at a rate significantly above chance, $\beta=0.71, S E=0.28, z=2.51, p=0.012$. These responses suggest that learners did extract some information about the CCC roots. However, correct responses to NewScrambled(Hard) items $\left(\mathrm{C}_{1} \mathrm{~V}_{\mathrm{X}} \mathrm{C}_{2} \mathrm{~V}_{\mathrm{Y}} \mathrm{C}\right.$ vs. $\left.\mathrm{C}_{1} \mathrm{~V}_{\mathrm{A}} \mathrm{C}_{3} \mathrm{~V}_{\mathrm{B}} \mathrm{C}_{2}\right)$, with a mean of $0.51, C I \pm 0.085$, were not selected at a rate significantly above chance, $\beta=0.031, S E=0.25, z=0.12, p=0.90$. Correct responses to Old-New $\left(\mathrm{C}_{1} \mathrm{~V}_{\mathrm{A}} \mathrm{C}_{2} \mathrm{~V}_{\mathrm{B}} \mathrm{C}_{3}\right.$ vs. $\left.\mathrm{C}_{1} \mathrm{~V}_{\mathrm{X}} \mathrm{C}_{2} \mathrm{~V}_{\mathrm{Y}} \mathrm{C}_{3}\right)$ items, with a mean of $0.75, C I \pm 0.074$ were selected at a rate significantly above chance, $\beta=1.15, S E=0.27, z=4.25, p<0.001$, suggesting that learners had were able to differentiate between novel and familiar items.

To further investigate whether participants were able to recognize novel items, we compared responses to responses to Old-New items to each of the other four test conditions via

\footnotetext{
${ }^{5}$ Many models received singular fit warnings. When the structure of the model was reduced, the warnings, and the results were generally identical or very similar to the more complex model.
} 
pairwise comparisons. There were significantly more correct responses to Old-New items compared to New-Scrambled(Hard) items, $\beta=1.12, S E=0.37, z=3.03, p=0.0024$, but no significant differences between and Old-New and Old-Scrambled items, $\beta=0.53, S E=0.40, z=$ $1.13, p=0.19$, New-Scrambled(Easy) items, $\beta=0.035, S E=0.38, z=0.92, p=0.93$, or NewNonWordHybrid items, $\beta=0.46, S E=0.37, z=1.22, p=0.22$. These results suggest that participants were able to memorize the 24 training items that were presented to them, but could only extend the pattern to novel items if the comparison item was sufficiently different from individual training items.

\section{Discussion}

Participants in Experiment 1 selected the 'correct' response at a rate significantly above chance on all types of test items, except for the New-Scrambled(Hard) items, which tested participants' ability to distinguish between novel items and familiar items with the consonants in the second syllable switched. As noted above, the ungrammatical option in these items are highly similar to grammatical items, which may have made it more difficult for participants to differentiate between the grammatical and ungrammatical items. In addition, the grammatical and ungrammatical items often differed by only a single phonological feature (e.g., voicing, place of articulation, manner of articulation), thus increasing the confusability between the grammatical and the ungrammatical items.

While participants did not select grammatical items at a rate greater than chance for NewScrambled(Hard) items, participants successfully identified novel items when compared to the $\mathrm{C}_{3} \mathrm{~V}_{\mathrm{A}} \mathrm{C}_{1} \mathrm{~V}_{\mathrm{B}} \mathrm{C}_{2}$ ungrammatical or the NonWord Hybrid items. These results suggest that learners did not form generalizations about the possible locations of consonants in words (e.g., words can start with /p/), but rather with reference to the specific consonants in the word (e.g., /p/, /t/ and 
$/ \mathrm{k} /$ can appear in a word, together in that order.

The results of Experiment 1 suggest that it is possible to form associations between nonadjacent consonantal roots without any reference to semantics, when there were only 12 consonant patterns, repeated many times. However, the high rate of repetition ( 24 items repeated 15 times) allowed for participants to memorize the individual items, which allowed them to distinguish between novel and familiar items, even when both were grammatical. This raises the question of whether it is possible to form a broader generalization about CCC roots without memorizing a small number of items. Experiments 2 and 3 explore this possibility by using a large number of different items in the training set, with different templates.

\section{Experiment 2}

In Experiment 2, we exposed participants to an increased number of templates that consonant and vowel patterns could fit into (e.g., CVCVC, CVCCV, VCVCVC, VCCVC and CVCVCV).

\section{Participants}

All participants were adult monolingual native English speakers. Eight participants were recruited from the University of Rochester community. All participants were paid $\$ 10$ for their participation..$^{6}$

\section{Materials}

Participants in Experiment 2 were exposed to the same general language as Experiment 1, with $12 \mathrm{CCC}$ consonantal roots. In addition to the $24 \mathrm{CCC}$ roots and VV patterns that were fit to the CVCVC template found in Experiment 1, participants in Experiment 2 were exposed to four

\footnotetext{
${ }^{6}$ An additional eight participants were run on a separate Language B, but were not included in the analysis because, due to Experimenter error, the training set included incorrect test items, and an increased exposure period.
} 
additional templates- $\mathrm{CoCCu}, \mathrm{iCiCiC}, \mathrm{eCCaC}$, and $\mathrm{CuCoCi}$. All $12 \mathrm{CCC}$ roots were fit into the four additional templates to create 48 additional items, for a total of 72 training items. The test items were identical to those in Experiment 1.

\section{Procedure}

The procedure of Experiment 2 was identical to Experiment 1 except that because the exposure set included 72 items (as opposed to 24), participants heard the exposure set five times instead of 15 (thus matching the total number of items in the exposure phase).

\section{Results}

The data for Experiment 2 were analyzed in the same manner as Experiment 1. Means and standard errors of the mean can be found in Figure 1.

Correct responses to Old-Scrambled $\left(\mathrm{C}_{1} \mathrm{~V}_{\mathrm{A}} \mathrm{C}_{2} \mathrm{~V}_{\mathrm{B}} \mathrm{C}_{3}\right.$ vs. $\left.\mathrm{C}_{1} \mathrm{~V}_{\mathrm{A}} \mathrm{C}_{3} \mathrm{~V}_{\mathrm{B}} \mathrm{C}_{2}\right)$ items, with a mean of $0.83, C I \pm 0.095$, were selected at a rate significantly above chance, $\beta=1.79, S E=0.47, z=$ 3.83, $p<0.001$. Correct responses to New-Scrambled(Easy) $\left(\mathrm{C}_{1} \mathrm{~V}_{\mathrm{X}} \mathrm{C}_{2} \mathrm{~V}_{\mathrm{Y}} \mathrm{C}_{3}\right.$ vs. $\left.\mathrm{C}_{3} \mathrm{~V}_{\mathrm{A}} \mathrm{C}_{1} \mathrm{~V}_{\mathrm{B}} \mathrm{C}_{2}\right)$ items, with a mean of $0.72, C I \pm 0.11$ were selected at a rate significantly above chance, $\beta=$ 1.06, $S E=0.42, z=2.535, p=0.011$. Correct responses to New-NonWord Hybrid (NWH) items $\left(\mathrm{C}_{1} \mathrm{~V}_{\mathrm{X}} \mathrm{C}_{2} \mathrm{~V}_{\mathrm{Y}} \mathrm{C}_{3}\right.$ vs. $\left.\left(\mathrm{C}_{1} \mathrm{~V}\right)\left(\mathrm{C}_{2} \mathrm{VC}_{3}\right)\right)$ with a mean of $0.67, C I \pm 0.12$, were selected at a rate significantly above chance, $\beta=0.85, S E=0.41, z=2.04, p=0.041$. However, correct responses to New-Scrambled(Hard), with a mean of $0.52, C I \pm 0.13$ items were not significantly above chance, $\beta=0.071, S E=0.39, z=0.18, p=0.86$. In addition, correct responses to Old-New $\left(\mathrm{C}_{1} \mathrm{~V}_{\mathrm{A}} \mathrm{C}_{2} \mathrm{~V}_{\mathrm{B}} \mathrm{C}_{3}\right.$ vs. $\left.\mathrm{C}_{1} \mathrm{~V}_{\mathrm{X}} \mathrm{C}_{2} \mathrm{~V}_{\mathrm{Y}} \mathrm{C}_{3}\right)$ items, with a mean of $0.69, C I \pm 0.12$, were selected at a rate significantly above chance, $\beta=0.94, S E=0.42, z=2.22, p=0.026$, suggesting that learners were able to differentiate between novel and familiar items. This pattern of results was identical to those of Experiment 1. 
To further investigate whether participants were able to recognize novel items, we compared responses to responses to Old-New items to each of the other four test conditions via pairwise comparisons. Correct responses to Old-New items were not significantly different from any of the other four test types of items- Old-Scrambled items, $\beta=0.86, S E=0.61, z=1.41, p=$ 0.16 , New-Scrambled(Easy) items, $\beta=0.12, S E=0.58, z=0.22, p=0.83$, New-

Scrambled(Hard) items, $\beta=0.86, S E=0.56, z=1.54, p=0.12$, or New-NonWord Hybrid items, $\beta=0.089, S E=0.61, z=0.16, p=0.88$. These results are similar to Experiment 1, except that New-Scrambled(Hard) items were not significantly different from Old-New items. These results suggest that participants were able to memorize the 24 training items that were presented to them, but could only extend the pattern to novel items if the comparison item was sufficiently different from individual training items.

\section{Discussion}

When participants were exposed to additional consonant-vowel word patterns, in addition to CVCVC, participants were able to recognize the consonant patterns. The pattern of results for Experiment 2 are mostly identical to Experiment 1, suggesting that the learning that occurred in Experiment 1 was not due to the relatively small number of items (24) repeated a large number of times (15), since Experiment 2 had triple the number of training items (repeated only five times), but a similar result (note that both experiments had the same number of training trials overall).

Experiments 1 and 2 demonstrated that variability of can exist in a variety of ways to allow learners to extract the regularities of consonant patterns. Experiment 1 showed learnability from repetition of small number of items, while Experiment 2 used variation in the syllable structure templates. Interestingly, languages of the world that contain non-concatenative 
morphology typically make use of a wide range of consonant-vowel patterns (they are often referred to as root-and-pattern languages). Experiment 3 demonstrates that when an artificial language is modified to be more like natural languages, learning persists.

Training participants on a non-concatenative language with variability similar to the kind of variability found in natural languages showed strong levels of learnability in adult participants. Another aspect of non-concatenative morphology in natural language is the fact that languages with non-concatenative morphology also include some form of concatenative morphology as well, such as prefixes and suffixes. It may be that the continuity of affixes around the discontinuous affixes in non-concatenative morphology also helps learners tune in to the regularities of the consonant patterns. The inclusion of concatenative morphology in the training set may help learners discover the consonant patterns for a few reasons. First, highly salient morphological structures may allow the learner to segment the target morphological structure (CCC roots) out from the words heard in training. Second, the inclusion of concatenative morphology may provide a link between different forms with the same CCC root pattern. For example, [mukitab] and [kitab] share the same final two syllables, which may provide a link to [kutub], which share the same three final consonants.

The inclusion of concatenative morphology in the training set could also hinder learning, since learners rely on edge-based cues to find patterns in non-adjacent dependencies (Wilson et al., 2020). Placing a prefix at the beginning of words can make it more difficult to find patterns in the consonants if learners rely on the beginnings and ends of words to find regularities in the consonantal roots, since the consonantal roots no longer appear at the beginning of the word in words with prefixes. Experiment 3 therefore tests whether inclusion of concatenative morphology helps or hinders the learnability of consonantal roots in non-concatenative 
morphology.

\section{Experiment 3}

Experiment 3 explores whether learners can extract regularities of consonantal roots from the presence of a highly salient prefix.

\section{Method}

\section{Participants}

All participants were adult monolingual native English speakers. Eight ${ }^{7}$ participants were recruited from the University of Rochester community. All participants were paid $\$ 10$ for their participation.

\section{Design and Materials}

Experiment 3 was designed with the same basic structure as Experiment 1, except that in addition to the 24 training items from Experiment 1, there were an additional 12 training items that included the prefix [mu-] (the stems of these 12 affixed items were the same as those in the 24 unaffixed forms). This created a total of 36 items included in training. Test items in Experiment 3 were identical to those in Experiments 1-2.

\section{Procedure}

The procedure was identical to Experiments 1 and 2, except that participants heard the training set 10 times rather than five or 15 . This was because there were only 36 training items in Experiment 4, as opposed to 72 in Experiment 2 or 24 in Experiment 1.

\section{Results}

Data from Experiment 3 were analyzed in the same manner as Experiments 1-2. Means and standard errors of the mean can be found in Figure 1.

\footnotetext{
${ }^{7}$ An additional eight participants were run on a separate 'Language B', but were excluded due to experimenter error, and irregularities in the training items.
} 
Correct responses to Old-Scrambled $\left(C_{1} V_{A} C_{2} V_{B} C_{3}\right.$ vs. $\left.C_{1} V_{A} C_{3} V_{B} C_{2}\right)$ items, with a mean of $0.80, C I \pm 0.10$, were selected at a rate significantly above chance, $\beta=1.41, S E=0.34, z=$ 4.10, $p<0.001$. Correct responses to New-Scrambled(Easy) $\left(\mathrm{C}_{1} \mathrm{~V}_{\mathrm{X}} \mathrm{C}_{2} \mathrm{~V}_{\mathrm{Y}} \mathrm{C}_{3}\right.$ vs. $\left.\mathrm{C}_{3} \mathrm{~V}_{\mathrm{A}} \mathrm{C}_{1} \mathrm{~V}_{\mathrm{B}} \mathrm{C}_{2}\right)$ items, with a mean of $0.72, C I \pm 0.11$, were selected at a rate significantly above chance, $\beta=$ 0.97, $S E=0.31, z=3.10, p=0.0019$. Correct responses to New-NonWord Hybrid (NWH) items $\left(\mathrm{C}_{1} \mathrm{~V}_{\mathrm{X}} \mathrm{C}_{2} \mathrm{~V}_{\mathrm{Y}} \mathrm{C}_{3}\right.$ vs. $\left.\left(\mathrm{C}_{1} \mathrm{~V}\right)\left(\mathrm{C}_{2} \mathrm{VC}_{3}\right)\right)$ with a mean of $0.625, C I \pm 0.12$, were selected at a rate above chance, but were only marginally significant, $\beta=0.53, S E=0.29, z=1.80, p=0.072$. Correct responses to New-Scrambled(Hard), with a mean of $0.39, C I \pm 0.12$ items were numerically (but not significantly) below chance, $\beta=-0.46, S E=0.29, z=-1.58, p=0.11$. Correct responses to Old-New $\left(\mathrm{C}_{1} \mathrm{~V}_{\mathrm{A}} \mathrm{C}_{2} \mathrm{~V}_{\mathrm{B}} \mathrm{C}_{3}\right.$ vs. $\left.\mathrm{C}_{1} \mathrm{~V}_{\mathrm{X}} \mathrm{C}_{2} \mathrm{~V}_{\mathrm{Y}} \mathrm{C}_{3}\right)$ items, with a mean of $0.69, C I \pm 0.12$ were selected at a rate significantly above chance, $\beta=0.82, S E=0.30, z=2.68, p=0.0074$, suggesting that learners were able to differentiate between novel and familiar items. This pattern of results was generally identical to those of Experiments 1-2, except that responses to New-Scrambled(Hard) trended below chance, and responses to New-NonWord Hybrid (NWH) items were only marginally significant. This could be due to a lack of statistical power, as there were only eight participants in the experiment.

To further investigate whether participants were able to recognize novel items, we compared responses to Old-New items to each of the other four test conditions via pairwise comparisons. Correct responses to Old-New items were significantly different from NewScrambled(Hard) items, $\beta=1.27, S E=0.42, z=3.03, p=0.00255$, but not any of the other three test types of items- Old-Scrambled items, $\beta=0.59, S E=0.45, z=1.30, p=0.19$, NewScrambled(Easy) items, $\beta=0.15, S E=0.43, z=0.35, p=0.73$, or New-NonWordHybrid items, $\beta=0.29, S E=0.42, z=1.30, p=0.19$. This pattern of results is identical to Experiment 1 . 
These results suggest that participants were able to distinguish between novel words and ungrammatical items, when those items were sufficiently different from familiar items. Participants were able to distinguish between novel and familiar items, suggesting a bias towards familiar items.

\section{Discussion}

The results of Experiment 3 parallel Experiments 1-2- adult participants learned some aspects of the consonant patterns within the non-concatenative morphological system. This suggests that the inclusion of a prefix did not sufficiently hinder learnability of the general consonantal roots, but it did not appear to help, either. While participants may make use of edges when learning non-adjacent dependencies, learners may ignore it if the edge material is sufficiently predictable. The prefixes are therefore neither helpful nor harmful to the use of edge information in extracting the consonantal roots.

As in Experiments 1-2, participants in Experiment 3 did not select items in the NewScrambled(Hard) items at a rate significantly different from chance, suggesting that participants did not have a strong representation of the consonantal roots, as they were only able to distinguish novel grammatical items from ungrammatical items if they were sufficiently different from the training items. Participants were also successful at distinguishing between Old and New items, despite having 72 items in the training set. This suggests that much of the representation of the consonantal roots may come from memorizing the items rather than learning the consonantal roots and vowel residues as rules to generate items in the language.

\section{General Discussion}

We have presented the results from three artificial language learning experiments on morpheme segmentation of non-adjacent, non-concatenative morphological patterns. Participants 
were exposed to words from a miniature, artificial language that contained 12 consonantal 'roots' and various vowel patterns. In Experiment 1, all forms had the same CVCVC template, while in Experiment 2, additional templates were added, and in Experiment 3, additional items contained a prefix. The general pattern of results was the same across all three experiments. Participants were able to learn the characteristics of the CVCVC words that they were trained on; they could differentiate words from the training set from ungrammatical items, as well as novel items that were not in the training set. This suggests that there was sufficient exposure of the items, so that participants could memorize the items heard in training. It also suggests that learners did not form an implicit abstract representation, where grammatical items are equally 'good', regardless of whether they were in the training set.

There were also three sets of test items that probed learners' ability to generalize the training set to novel items; the results of these were mixed. When comparing novel items to a 'scrambled' old item, participants selected the novel grammatical item at a rate greater than chance only when the first element of the CCC root was moved to the second position (termed 'easy'). Participants failed to distinguish novel grammatical items and scrambled old items when the scrambled old items had the same consonant in initial position (termed 'hard'), suggesting that learners made use of edge information and perceptual similarity, as the 'hard' items were more perceptually similar to items in the training set than 'easy' items. However, perceptual similarity alone cannot explain this difference, as participants were successful in distinguishing between novel words and nonword hybrids, where the first element of one root was paired with the second and third elements of a different root. This suggests that participants were not simply learning the location of where the items could appear in a word (e.g., /p/ can appear word initially, /b/ word finally), but some information (e.g., /p/, and /b/ appear in the same words). 
This suggests that participants learned something more than phonotactic restrictions.

\section{Learning Non-Adjacent Dependencies}

While the majority of previous research has focused on non-adjacent dependencies between words, or with word segmentation, the present study investigated non-adjacent dependencies within words, as in non-concatenative, root and pattern morphology found in languages like Hebrew and Arabic. While root and pattern morphology is found in natural languages, it is not a common pattern. Most languages have primarily concatenative morphology, and even languages with root and pattern morphology show large amounts of concatenative morphology. Thus, it is reasonable to assume that learners may show a bias against learning non-adjacent dependencies in words (Drake, 2018; Fullwood, 2018). The results of the present study support this, as participants were able to learn some regularities related to the consonantal patterns, they were not able to distinguish between novel items and ungrammatical items that were very similar to familiar items.

It has been hypothesized that cases of non-adjacent dependencies in natural language are highly constrained in order to avoid or manage the high computational complexity that nonadjacent dependencies bring. Wilson et al. (2020) discuss several factors that may help learners find non-adjacent dependencies in the speech stream. For example, Gomez (2002) found that participants were better at learning non-adjacent dependencies when the variability of the intervening items in non-adjacent dependencies increased. The idea is that the high variability of intervening elements made the regular dependencies 'stand out'. In the present study, the variability was found not in the interleaving vowel elements, but in the consonantal roots. While this is the opposite distributional cue, it may have the same effect. For example, if the vowels in the CVCVC words were always the same vowel (e.g., $\mathrm{CaCaC}$ ) then the vowels become 
uninformative and predictable, making it easier to find regularities between the consonants. While the present study used four vowel patterns, it is possible that the lower variability in the vowels made it easier to find the regularities for the consonantal roots.

Perceptual similarity can also help items 'stand out', as learners were able to segment speech based on patterns based on consonants rather than syllables (Newport \& Aslin, 2004). If representations of consonants and vowels are kept at separate tiers (Heinz, 2010), then dependencies between consonants can be considered adjacent on the tier, despite intervening vowels. Even without proposed tiers, non-adjacent dependencies in phonology often rely on natural classes that share perceptual similarities, such as consonant harmony (Hansson, 2001; Rose \& Walker, 2011). In speech segmentation, prosodic cues can also provide an important cue to segmentation (Grama et al., 2016). Participants in the present study may have relied on perceptual similarity is that in the present set of experiments the non-concatenative patterns assumed a distinction between consonants and vowels, and the consistency across words lies in the CCC roots. The decision to separate consonants and vowels in this way in the artificial languages stems from two related underlying assumptions. First, consonants and vowels are believed to be separable entities, both linguistically and cognitively (Bonatti et al., 2007; Mehler et al., 2006; Toro et al., 2008). Second, non-concatenative languages are structured such that the consistencies and variation among roots is in the consonant roots and vowel patterns. Fullwood (2018) directly compared learnability of non-concatenative morphology that made a distinction between consonants and vowels, and one that did not, and found a bias against non-concatenative morphology that showed a mix of consonants and vowels. Finley and Newport (2020) did not show any learning impairment for words with roots that contained a mix of consonants and vowels compared to roots with just consonants. However, participants did show similar learning 
impairments, and were unable to differentiate between new and old items, suggesting that participants may not have been able to articulate the relationships between the consonants and vowels in an explicit manner.

\section{Relation to Linguistic Typology}

The results of the present experiments may shed light on understanding the role of learnability in linguistic typology. Previous results from artificial grammar learning experiments has demonstrated that typologically frequent and representationally simple patterns are the easiest patterns to learn (Culbertson et al., 2012; Culbertson \& Newport, 2015; Culbertson \& Smolensky, 2010; Fedzechkina et al., 2016; Finley, 2012; Finley \& Badecker, 2007, 2008; Moreton, 2008). This supports a view of language learning and typology in which patterns in languages that have the distributional properties that make them easiest to learn will be the ones that persist across generations of speakers and learners. In this manner, the structure found in languages is not arbitrary or accidental. Rather, linguistic structure contains the types of distributional information that learners are biased to attend to, remember and form generalizations over.

The present experiments may shed some light on this hypothesis. Participants were able to extract some, but not all regularities from the CCC roots. As noted above, this could be due to a general bias against non-concatenative morphology. Drake (2018) showed a bias against nonconcatenative morphology in both English, Arabic, and Maltese speakers, with a reduced bias for speakers whose L1 contained consistent non-concatenative morphology. Fullwood (2018) also showed a bias against non-concatenative morphology, with a stronger bias against roots that did not conform to consonantal structure. This suggests that learners even when learners are exposed to non-concatenative morphology in their native language, they still show a bias towards 
concatenative morphology, and that non-concatenative morphology is preferentially structured to contain consonantal roots over vowel roots. All of these learning biases mirror the typology of the world's languages.

In addition, adding additional structure to the artificial language did not impair the learnability of the CCC roots. While learners may be biased to use edges as a way to find regularities in the speech stream, participants learned some aspects of the consonantal roots when some items contained a prefix. However, participants were numerically (but not significantly) below chance for New-Scrambled(Hard) items, and did not show a significant difference for New-NonWordHybrid items. This suggests that learners do not blindly use edges to extract regularities, but are sensitive to the structure of the words. Learnability was not affected when additional templates were added, creating increased variability in the lexical items, which could, in principle have made the learning problem harder. Interestingly, the additional structure (a prefix and additional templates) are all structures commonly found in natural languages, which is suggestive of how languages with non-concatenative morphology might contain structures that are supportive of learnability. Because we did not compare the learnability of a nonconcatenative language with additional structures that are not found in natural language, we cannot say whether the same results would be obtained if structures that are not found in natural language were included. This is a question for future research.

\section{Limitations}

While the current study offers several important insights into learnability of non-adjacent dependencies in morpheme segmentation, there are limitations that could be addressed in future research. First, the sample sizes across the experiments (especially Experiments 2-3) were very small, and only contained one language (rather than two different sets of languages to counter 
any idiosyncrasies in the stimuli that might affect results). However, it is important to note that the same general pattern of results held across all three experiments, and in general, the results that were statistically significant were significant at a high level, suggesting that the effects seen in the present study were robust and replicate well.

In many word segmentation experiments that explore distributional learning, transitional probabilities are directly calculated (Saffran et al., 1996) and compared in the test items, but this was not done in the present study. It is possible that some of the idiosyncrasies in the findings of the present study could be better understood with a more robust control of the transitional probability and lexical statistics. One specific issue to be addressed could be to better understand the role of edge effects and perceptual similarity. For example, the low performance on NewOld-Scrambled(hard) items could be explained in terms of edge effects, as in these items the first and the third consonant had switched places in the scrambled items, but also in terms of perceptual similarity, as the hard scrambled items were more perceptually similar to the old items compared to the easy scrambled items. Future research could work to tease apart this bias.

\section{Questions for Future Research}

The present experiments shed light on several issues related to the learnability of nonadjacent dependencies in morpheme segmentation. The results suggest that learners are biased against non-adjacent dependencies in morpheme segmentation, but that they can still extract regularities from words. However, there are several questions left for future research. One important question is how the mechanisms related to learning non-adjacent dependencies in other areas of language relate to non-concatenative morphology. Because the regularities in nonconcatenative morphology are highly related to phonotactic regularities, it is possible that the constraints that govern non-adjacent dependencies in phonotactic patterns (e.g., vowel and 
consonant harmony) are related to non-concatenative morphology. One example of this is that roots in non-concatenative morphology follow constraints on similarity and repetition, known as the Obligatory Contour Principle (OCP) (Frisch et al., 2004; McCarthy, 1986), and consonant harmony patterns are also subject to constraints on similarity (Hansson, 2001; Mackenzie, 2011; Rose \& Walker, 2004). Understanding how constraints on similarity and the OCP affect the learnability of consonantal roots in non-concatenative morphology, is something that is still being understood.

While there are clear connections between the constraints that govern consonantal roots in non-concatenative morphology with phonotactic and phonological processes, it is less clear whether and how the constraints that govern non-adjacent dependencies at the sentence level are the same as those in morphology. More research is needed to better understand the mechanisms that learners use to parse morphological, and syntactic structures, and whether these structures run parallel to each other. While much research has been done to better understand how learners cope with non-adjacent dependencies at the sentence level and in word segmentation, there is still very little attention to morphological processing and morpheme segmentation. While the present paper adds to the literature on morpheme segmentation in non-adjacent structures, more research is needed to better connect these different processes.

Learners make use of a variety of cues to parse non-adjacent dependencies, including edge effects, perceptual similarity, distributional cues, and attentional factors (Wilson et al., 2020), but it does seem that any single cue is necessary or sufficient to learning non-adjacent dependencies. While attentional factors have been directly addressed, it is not clear whether 'non-attentional' cues like perceptual effects and prosody may be proxies for attentional factors. For example, pretraining on adjacent dependencies facilitates learning non-adjacent 
dependencies (Lany \& Gómez, 2008), but this could also be an attentional cue, as the pretraining allows learners to attend to non-adjacent factors. Non-attentional cues may serve to boost the signal of the non-adjacent dependencies, allowing for more attentional resources to learning the non-adjacent dependencies. If this is the case, it may be that the main factor in learning nonadjacent dependencies is attentional, rather than linguistic. More research is needed to better understand how linguistic and attentional cues interact for learning non-adjacent dependencies.

\section{Conclusion}

The present study explored the learnability of consonantal roots in a miniature language with non-concatenative, root and pattern morphology. Adult, English speaking learners were able to extract regularities of the consonantal roots, but only when participants were comparing novel items to an ungrammatical item that was sufficiently different from the exposure set. This suggests that while learners can parse non-concatenative morphology without reference to meaning, there are biases against such parsing, and that learners make use of perceptibility and edge-based cues to find these regularities. 


\section{References}

Barr, D. J., Levy, R., Scheepers, C., \& Tily, H. J. (2013). Random effects structure for confirmatory hypothesis testing- Keep it maximal. Journal of Memory and Language, 68(3), 255-278. https-//doi.org/10.1016/j.jml.2012.11.001

Bat-El, O. (1994). Stem modification and cluster transfer in Modern Hebrew. Natural Language \& Linguistic Theory, 12(4), 571-596.

Bates, D., Mächler, M., Bolker, B., \& Walker, S. (2015). Fitting linear mixed-effects models using \{lme4\}. Journal of Statistical Software, 67, 1-48. https//doi.org/10.18637/jss.v067.i01

Beckman, J. N. (1997). Positional faithfulness, positional neutralisation and Shona vowel harmony. Phonology, 14, 1-46. https-//doi.org/10.1017/S0952675797003308

Bonatti, L. L., Peña, M., Nespor, M., \& Mehler, J. (2005). Linguistic constraints on statistical computations- the role of consonants and vowels in continuous speech processing. Psychological Science - A Journal of the American Psychological Society / APS, 16(6), 451-459. https-//doi.org/10.1111/j.0956-7976.2005.01556.x

Bonatti, L. L., Peña, M., Nespor, M., \& Mehler, J. (2007). On consonants, vowels, chickens, and eggs. Psychological Science, 18(10), 924-925. https-//doi.org/10.1111/j.14679280.2007.02002.x

Culbertson, J., \& Newport, E. L. (2015). Harmonic biases in child learners- In support of language universals. Cognition, 139, 71-82. https-//doi.org/10.1016/j.cognition.2015.02.007

Culbertson, J., \& Smolensky, P. (2010). Testing Greenberg's Universal 18 using the Mixture Shift Paradigm for artificial language learning. NELS, 40.

Culbertson, J., Smolensky, P., \& Legendre, G. (2012). Learning biases predict a word order 
universal. Cognition, 122, 306-329. https-//doi.org/10.1016/j.cognition.2011.10.017

de Diego-Balaguer, R., Martinez-Alvarez, A., \& Pons, F. (2016). Temporal attention as a Scaffold for language development. Frontiers in Psychology, 7(February), 1-15. https//doi.org/10.3389/fpsyg.2016.00044

Drake, S. N. (2018). L1 Biases in Learning Root-and-Pattern Morphology. University of Arizona.

Endress, A. D., \& Bonatti, L. L. (2007). Rapid learning of syllable classes from a perceptually continuous speech stream. Cognition, 105(2), 247-299. https//doi.org/10.1016/j.cognition.2006.09.010

Fedzechkina, M., Newport, E. L., \& Jaeger, T. F. (2016). The miniature artificial language learning paradigm as a complement to typological data. In T. Ortega, L., H. I. A., Park, \& M. Uno (Eds.), The usage-based study of language learning and multilingualism (pp. 211232). Georgetown University Press.

Finley, S. (2011). The privileged status of locality in consonant harmony. Journal of Memory and Language, 65(1), 74-83.

Finley, S. (2012). Typological asymmetries in round vowel harmony- Support from artificial grammar learning. Language and Cognitive Processes, 27(10), 1550-1562. https//doi.org/10.1080/01690965.2012.660168

Finley, S. (2015). Learning nonadjacent dependencies in phonology- Transparent vowels in vowel harmony. Language, 91(1), 48-72. https-//doi.org/10.1353/lan.2015.0010

Finley, S., \& Badecker, W. (2007). Towards a substantively biased theory of learning. Berkeley Linguistics Society, 33, 142-154.

Finley, S., \& Badecker, W. (2008). Analytic biases for vowel harmony languages. In N. Abner \& 
J. Bishop (Eds.), West Coast Conference of Formal Linguistics (Vol. 27, pp. 168-176).

Finley, S., \& Newport, E. N. (2021). Non-concatenative morpheme segmentation in adults and children. https-//doi.org/https-//doi.org/10.31234/osf.io/bmfaj

Frisch, S., Pierrehumbert, J. B., \& Broe, M. B. (2004). Similarity avoidance and the OCP. Natural Language \& Linguistic Theory, 22(1), 179-228.

Frost, R. L. A., \& Monaghan, P. (2016). Simultaneous segmentation and generalisation of nonadjacent dependencies from continuous speech. Cognition, 146, 70-74. https//doi.org/https-//doi.org/10.1016/j.cognition.2015.11.010

Fullwood, M. A. (2018). Biases in segmenting non-concatenative morphology. PhD Dissertation, MIT.

Fullwood, M. A., \& O’Donnell, T. J. (2013). Learning non-concatenative morphology. In Proceedings of the Workshop on Cognitive Modeling and Computational Linguistics (pp. 21-27). Association for Computational Linguistics.

Gomez, R. L. (2002). Variability and detection of invariant structure. Psychological Science, $13(5), 431-436$.

Gomez, R. L., \& Maye, J. (2005). The developmental trajectory of nonadjacent dependency learning. Infancy, 7(2), 183-206.

Grama, I. C., Kerkhoff, A., \& Wijnen, F. (2016). Gleaning structure from sound- The role of prosodic contrast in learning non-adjacent dependencies. Journal of Psycholinguistic Research, 45(6), 1427-1449. https-//doi.org/https-//doi.org/10.1007/s10936-016-9412-8

Hansson, G. Ó. (2001). Theoretical and typological issues in consonant harmony. PhD Dissertation University of California, Berkeley.

Heinz, J. (2010). Learning long-distance phonotactics. Linguistic Inquiry, 41(4), 623-661. 
Lany, J., \& Gómez, R. L. (2008). Twelve-month-old infants benefit from prior experience in statistical learning. Psychological Science, 19(12), 1247-1252. https//doi.org/10.1111/j.1467-9280.2008.02233.x

Mackenzie, S. (2011). Contrast and the evaluation of similarity- Evidence from consonant harmony. Lingua, 121(8), 1401-1423. https-//doi.org/10.1016/j.lingua.2011.03.004

Marchetto, E., \& Bonatti, L. L. (2013). Words and possible words in early language acquisition. Cognitive Psychology, 67(3), 130-150. https-//doi.org/10.1016/j.cogpsych.2013.08.001

McCarthy, J. J. (1986). OCP effects- Gemination and antigemination. Linguistic Inquiry, 17(2), 207-263.

McCarthy, J. J., \& Prince, A. (1990). Prosodic morphology and templatic morphology. In M. Eid \& J. McCarthy (Eds.), Perspectives on Arabic Linguistics- Papers from the Second Symposium (pp. 1-54). Benjamins.

McMullin, K., \& Hansson, G. Ó. (2014). Locality in long-distance phonotactics- evidence for modular learning. In Proceedings of NELS 44.

McMullin, K., \& Hansson, G. Ó. (2019). Inductive learning of locality relations in segmental phonology. Laboratory Phonology, 10(1), 14. https-//doi.org/10.5334/labphon.150

Mehler, J., Peña, M., Nespor, M., \& Bonatti, L. L. (2006). The "Soul” of Language does not use Statistics- Reflections on Vowels and Consonants. Cortex, 42(6), 846-854. https//doi.org/10.1016/S0010-9452(08)70427-1

Misyak, J. B., \& Christiansen, M. H. (2007). Extending statistical learning farther and furtherLong-distance dependencies, and individual differences in statistical language learning. In D. S. McNamara \& J. G. Trafton (Eds.), Proceedings of the 29th Annual Conference of the Cognitive Science Society (pp. 1307-1312). Cognitive Science Society. 
Misyak, J. B., Christiansen, M. H., \& Tomblin, B. (2009). Statistical learning of nonadjacent dependencies predicts on-line processing of long-distance dependencies in natural language. In N. Taatgen \& H. van Rijn (Eds.), Proceedings of the 31st Annual Conference of the Cognitive Science Society (pp. 177-182). Cognitive Science Society.

Moreton, E. (2008). Analytic bias and phonological typology. Phonology, 25(01), 83-127. https//doi.org/10.1017/S0952675708001413

Newport, E. L., \& Aslin, R. N. (2004). Learning at a distance I. Statistical learning of nonadjacent dependencies. Cognitive Psychology, 48, 127-162.

Onnis, L., Monaghan, P., Richmond, K., \& Chater, N. (2005). Phonology impacts segmentation in online speech processing. Journal of Memory and Language, 53(2), 225-237. https//doi.org/10.1016/j.jml.2005.02.011

Peña, M., Bonatti, L. L., Nespor, M., \& Mehler, J. (2002). Signal-driven computations in speech processing. Science, 298, 604-607.

R Development Core Team, R. (2018). R- A language and environment for statistical computing. In R. D. C. Team (Ed.), R Foundation for Statistical Computing (Vol. 1, Issue 2.11.1, p. 409). R Foundation for Statistical Computing. https-//doi.org/10.1007/978-3-540-74686-7

Reeder, P., Newport, E. L., \& Aslin, R. (2013). From shared context to syntactic categories- The role of distributional information in learning linguistic form-classes. Cognitive Psychology, $66,30-54$.

Rose, S., \& Walker, R. (2004). A typology of consonant agreement as correspondence. Language, 80(March), 475-531. https-//doi.org/10.1353/lan.2004.0144

Rose, S., \& Walker, R. (2011). Harmony systems. In J. Goldsmith, J. Riggle, \& A. Yu (Eds.), Handbook of Phonological Theory (2nd ed.) (pp. 240-290). Blackwell. 
RStudio Team. (2020). RStudio- Integrated Development for R. 2020. http-//www.rstudio.com/

Saffran, J. R., Aslin, R. N., \& Newport, E. L. (1996). Statistical learning by 8-month-olds. Science, 274, 1926-1928.

Toro, J. M., Nespor, M., Mehler, J., \& Bonatti, L. L. (2008). Finding words and rules in a speech stream- Functional differences between vowels and consonants. Psychological Science, 19, $137-144$.

Toro, J. M., Sinnett, S., \& Soto-Faraco, S. (2011). Generalizing linguistic structures under high attention demands. Journal of Experimental Psychology-Learning, Memory, and Cognition3, 37(2), 492.

Wang, F. H., \& Mintz, T. H. (2018). Learning Non-Adjacent Dependencies Embedded in Sentences of an Artificial Language- When Learning Breaks Down. Journal of Experimental Psychology- Learning, Memory, and Cognition, 44(4), 604-614. https//doi.org/10.1017/CBO9781107415324.004

Wang, F. H., Zevin, J., \& Mintz, T. H. (2017). Top-down structure influences learning of nonadjacent dependencies in an artificial langauge. Joirnal of Experimental PsychologyLearning, Memory, and Cognition, 146(12), 1738.

Wilson, B., Spierings, M., Ravignani, A., Mueller, J. L., Mintz, T. H., Wijnen, F., van der Kant, A., Smith, K., \& Rey, A. (2020). Non-adjacent Dependency Learning in Humans and Other Animals. Topics in Cognitive Science, 12(3), 843-858. https-//doi.org/10.1111/tops.12381 
Table 1

Examples of Training Items

\begin{tabular}{lll} 
CCC Root & $\begin{array}{l}\text { CVCVC } \\
\text { Templates } \\
\text { (Experiments 1-3) }\end{array}$ & $\begin{array}{l}\text { Added } \\
\text { Templates } \\
\text { (Experiment 2) }\end{array}$ \\
\hline fks & fikas, fikis & ifikis, fukosi \\
bdg & bidag, bidig & budogi, ebdag \\
kts & kitas, kutis & epkat, koptu \\
dzg & duzig, dazug & duzogi, dozgu
\end{tabular}


Table 2

Examples of Test Items

\begin{tabular}{l|l|l} 
Test Item & Templates & Examples \\
\hline Old-Scrambled & $\mathrm{C}_{1} \mathrm{~V}_{\mathrm{A}} \mathrm{C}_{2} \mathrm{~V}_{\mathrm{B}} \mathrm{C}_{3}$ vs. $\mathrm{C}_{1} \mathrm{~V}_{\mathrm{A}} \mathrm{C}_{3} \mathrm{~V}_{\mathrm{B}} \mathrm{C}_{2}$ & $\begin{array}{l}\text { kaput vs. *katup } \\
\text { tipis vs. *tisip }\end{array}$ \\
New-Scrambled(Easy) & $\mathrm{C}_{1} \mathrm{~V}_{\mathrm{X}} \mathrm{C}_{2} \mathrm{~V}_{\mathrm{Y}} \mathrm{C}_{3}$ vs. $\mathrm{C}_{3} \mathrm{~V}_{\mathrm{A}} \mathrm{C}_{1} \mathrm{~V}_{\mathrm{B}} \mathrm{C}_{2}$ & $\begin{array}{l}\text { } \\
\text { fukis vs. *sifik } \\
\text { tapus vs. *sitip }\end{array}$ \\
New-Scrambled(Hard) & $\mathrm{C}_{1} \mathrm{~V}_{\mathrm{X}} \mathrm{C}_{2} \mathrm{~V}_{\mathrm{Y}} \mathrm{C}_{3}$ vs. $\mathrm{C}_{1} \mathrm{~V}_{\mathrm{A}} \mathrm{C}_{3} \mathrm{~V}_{\mathrm{B}} \mathrm{C}_{2}$ & $\begin{array}{l}\text { givaz vs. *giziv } \\
\text { tupis vs. *tisap }\end{array}$ \\
New-Non-Word Hybrid & $\mathrm{C}_{1} \mathrm{~V}_{\mathrm{X}} \mathrm{C}_{2} \mathrm{~V}_{\mathrm{Y}} \mathrm{C}_{3}$ vs. $\left(\mathrm{C}_{1} \mathrm{~V}\right)\left(\mathrm{C}_{2} \mathrm{VC}_{3}\right)$ & $\begin{array}{l}\text { badug vs. *bugav } \\
\text { sukat vs. *sukus }\end{array}$ \\
Old-New & $\mathrm{C}_{1} \mathrm{~V}_{\mathrm{A}} \mathrm{C}_{2} \mathrm{~V}_{\mathrm{B}} \mathrm{C}_{3}$ vs. $\mathrm{C}_{1} \mathrm{~V}_{\mathrm{X}} \mathrm{C}_{2} \mathrm{~V}_{\mathrm{Y}} \mathrm{C}_{3}$ & $\begin{array}{l}\text { sikat vs. *sakut } \\
\text { vazub vs. *vuzib }\end{array}$
\end{tabular}


Figure 1

Results: Experiments 1-3, Means and Standard Errors of the Mean

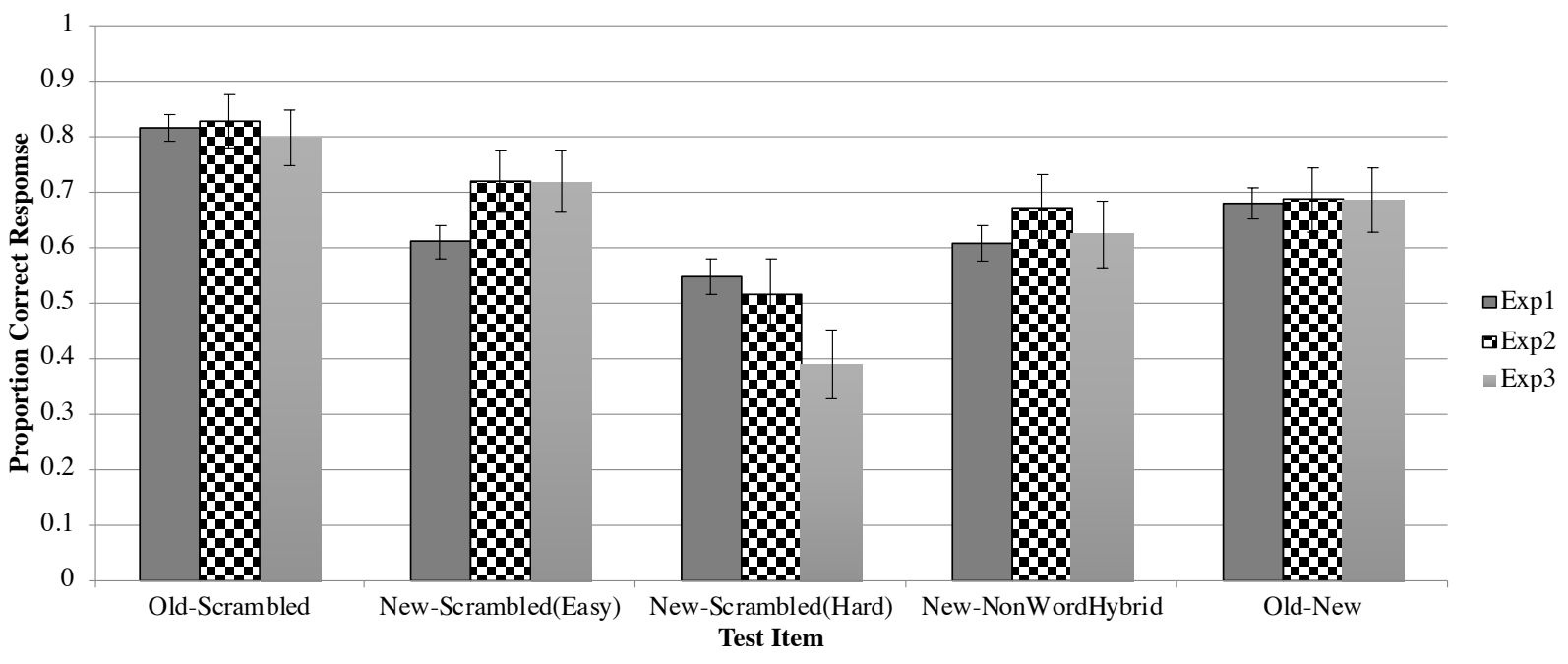




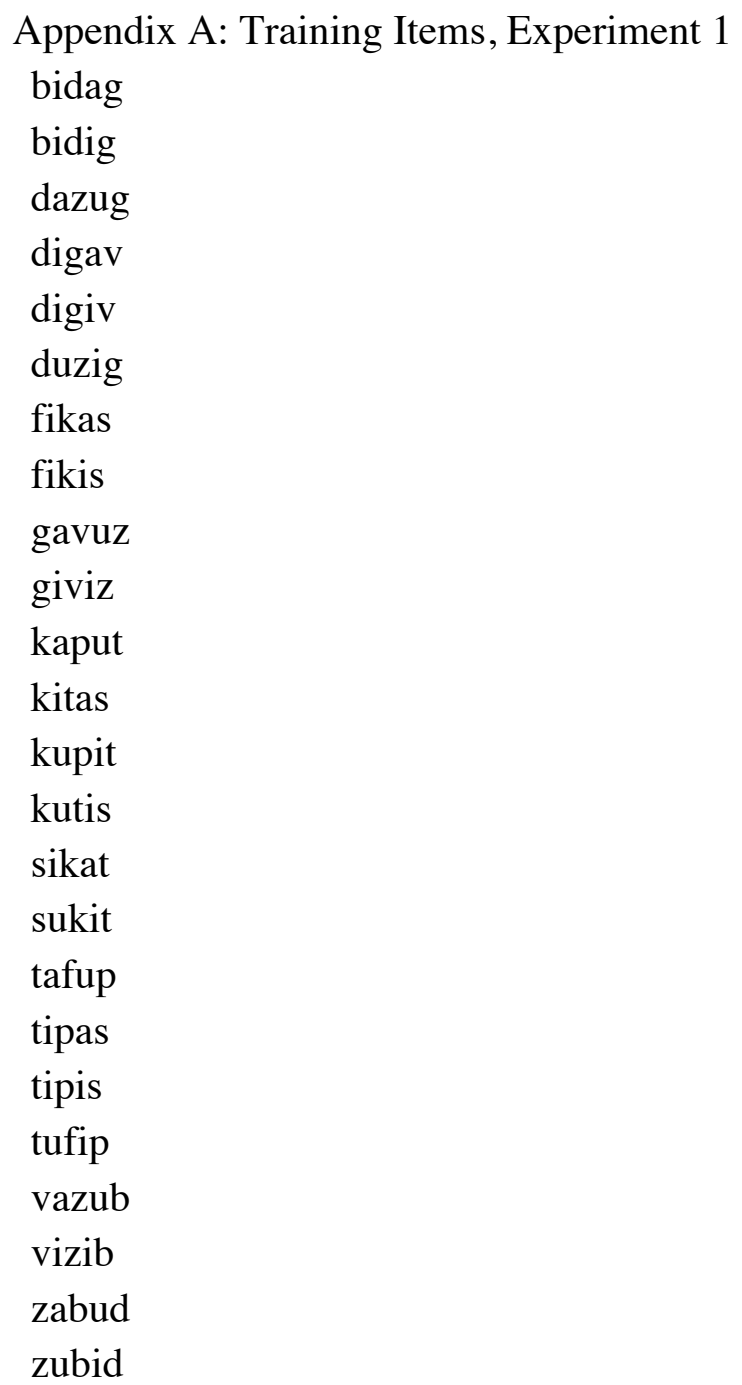


Appendix B: Test Items, Experiments 1-3

\begin{tabular}{|c|c|c|}
\hline Test Condition & Correct Response & Incorrect Response \\
\hline \multirow[t]{8}{*}{ Old-Scrambled } & bidig & bigid \\
\hline & fikas & fisak \\
\hline & gavuz & gazuv \\
\hline & kaput & katup \\
\hline & kitas & kisat \\
\hline & sukit & sutik \\
\hline & tipis & tisip \\
\hline & tufip & tupif \\
\hline \multirow[t]{8}{*}{ New-Scrambled (Easy) } & dizag & gudiz \\
\hline & sifak & fakus \\
\hline & dizig & gaduz \\
\hline & fukis & sifik \\
\hline & sikit & tisak \\
\hline & kipitL & takup \\
\hline & tapus & sitip \\
\hline & tifap & putif \\
\hline \multirow[t]{8}{*}{ New-Scrambled (Hard) } & badug & bigad \\
\hline & daguv & divig \\
\hline & dizig & daguz \\
\hline & givaz & giziv \\
\hline & kipat & kutip \\
\hline & tupis & tisap \\
\hline & zibad & zudib \\
\hline & zibid & zadub \\
\hline \multirow[t]{8}{*}{ New-NonWord Hybrid } & badug & bugav \\
\hline & dugiv & dadag \\
\hline & dizag & duzib \\
\hline & fukis & fikat \\
\hline & kipat & kafup \\
\hline & sakut & sukus \\
\hline & tifip & tukit \\
\hline & vuzib & vizug \\
\hline \multirow[t]{8}{*}{ Old-New } & digav & dugiv \\
\hline & fikis & fakus \\
\hline & kutis & katus \\
\hline & kitis & kutis \\
\hline & sikat & sakut \\
\hline & tafup & tifap \\
\hline & vazub & vuzib \\
\hline & vizib & vizab \\
\hline
\end{tabular}




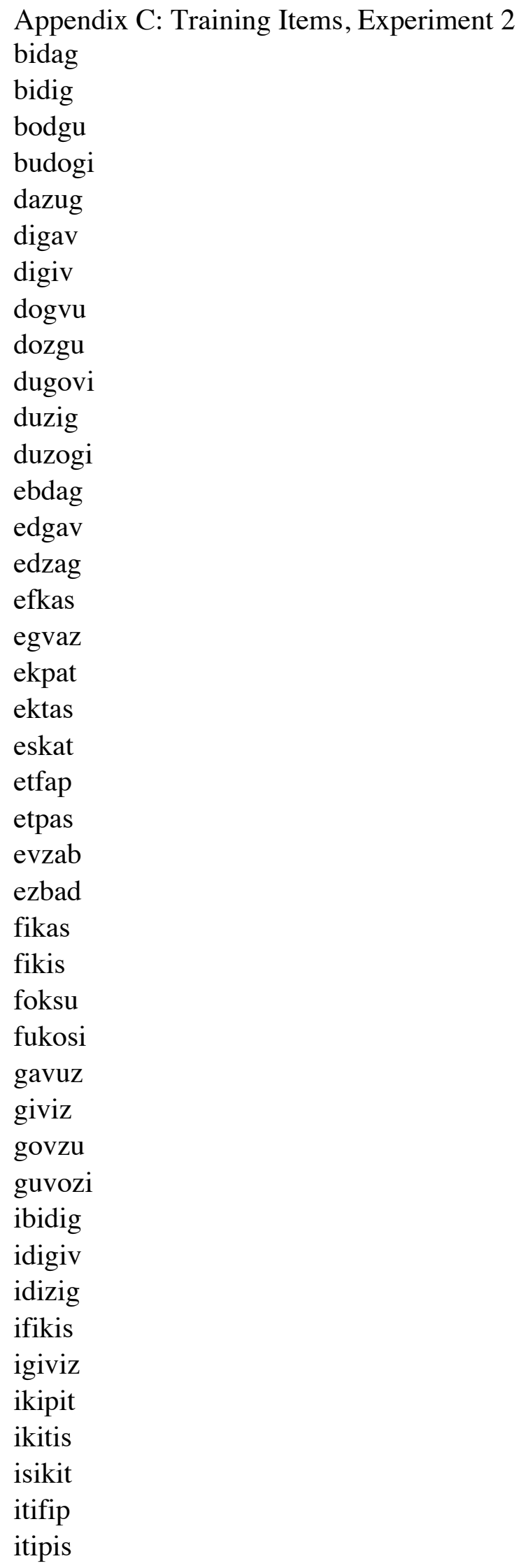


ivizib
izibid
kaput
kitas
koptu
kotsu
kupit
kupoti
kutis
kutosi
sikat
soktu
sukit
sukoti
tafup
tipas
tipis
tofpu
topsu
tufip
tufopi
tuposi
vazub
vizib
vozbu
vuzobi
zabud
zobdu
zubid
zubodi 


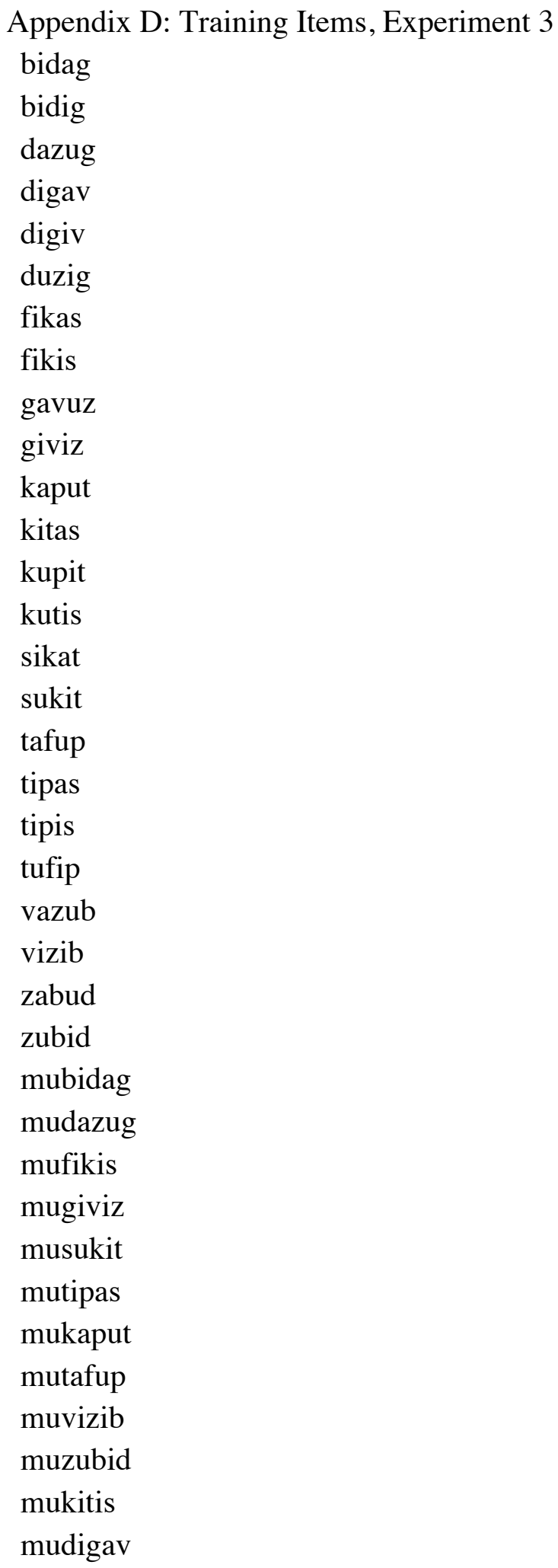

